\title{
Studies of Zn-poly(aniline-co-5-aminosalicylic acid) Aqueous Battery with Graphite Paper Current Collector
}

\author{
Zhuan Hu, Jinqing Kan ${ }^{*}$ \\ School of Chemistry and Chemical Engineering, Yangzhou University, Yangzhou, 225002, China \\ *E-mail: jqkan@yzu.edu.cn
}

doi: $10.20964 / 2017.09 .24$

Received: 31 April 2017 / Accepted: 2 July 2017 / Published: 13 August 2017

\begin{abstract}
Zn- PANI aqueous electrolyte secondary batteries have many advantages, such as low price and free of pollution, but some shortcomings still exist, for example, over-charge electrochemical degradation of the PANI, Zn passivation and Zn dendrite, especially current collector of PANI electrode is corroded easily. So far, how to overcome the many inherent questions of Zn- PANI secondary batteries is still a hot topic. Herein, an efficient strategy is proposed by increasing the electroactivity of current collector by potentiostatic deposition of poly (aniline-co-5-aminosalicylic acid) (PAASA) on graphite paper (PG, an excellent corrosion-resistant, low-cost, good conductivity, soft, elastic and light material) for collecting current. To study the electroactivity of the PAASA, cyclic voltammograms and electrochemical impedance spectra of PAASA cathode and $\mathrm{Zn}$ anode are measured in aqueous solution containing $\mathrm{NH}_{4} \mathrm{Cl}$ and $\mathrm{ZnCl}_{2}$. The electrochemical performances show that the specific capacity of the Zn-PAASA aqueous battery is $145 \mathrm{mAh} \mathrm{g}^{-1}$, which is far beyond that conventional Zn-PANI aqueous batteries under the same conditions, and retains $95 \mathrm{mAh} \mathrm{g}^{-1}$ of the capacity after 150 cycles. Thus, the Zn-PAASA secondary batteries may become the next generation of high-performance battery by further research.
\end{abstract}

Keywords: Poly (aniline-co-5-aminosalicylic acid); Zinc; aqueous secondary battery; Graphite paper; Current collector

\section{FULL TEXT}

(C) 2017 The Authors. Published by ESG (www.electrochemsci.org). This article is an open access article distributed under the terms and conditions of the Creative Commons Attribution license (http://creativecommons.org/licenses/by/4.0/). 